\title{
Apolipoprotein(a) and cardiovascular disease in Type 2 (non-insulin-dependent) diabetic patients with and without diabetic nephropathy
}

\author{
F. S. Nielsen ${ }^{1}$, A. I. Voldsgaard ${ }^{1}$, M.-A. Gall ${ }^{1}$, P. Rossing ${ }^{1}$, E.Hommel ${ }^{1}$, P. Andersen ${ }^{1}$, J. Dyerberg ${ }^{2}$ and H.-H.Parving $^{1}$ \\ ${ }^{1}$ Steno Diabetes Center, Gentofte, Denmark \\ ${ }^{2}$ Medi-Lab a.s., Copenhagen, Denmark
}

\begin{abstract}
Summary. The relative mortality from cardiovascular disease is on average increased five-fold in Type 2 (non-insulin-dependent) diabetic patients with diabetic nephropathy compared to non-diabetic subjects. We assessed the possible contribution of dyslipidaemia in general and elevated serum apolipoprotein(a) (apo(a)) in particular. Type 2 diabetic patients with normo-, micro- and macroalbuminuria were compared with healthy subjects. Each group consisted of 37 subjects matched for age, sex and diabetes duration. Serum creatinine in the nephropathy group was 105 (54740) $\mu \mathrm{mol} / \mathrm{l}$. The prevalence of ischaemic heart disease (resting ECG, Minnesota, Rating Scale) was 57, 35, 19 and $2 \%$ in macro-, micro- and normoalbuminuric diabetic patients and healthy subjects, respectively. The prevalence of ischaemic heart disease was higher in all diabetic groups as compared to healthy subjects $(p<0.05)$, and higher in macroalbuminuric as compared to normoalbuminuric diabetic patients $(p<0.01)$. There was no significant difference between apo(a) in the four groups: $161(10-1370), 191$ (10-2080), 147 (10-942), 102 (10-1440) U/l (median (range)) in macro-, micro- and normoalbuminuric groups and healthy subjects. Serum total-cholesterol, HDL-cholesterol and LDL-choles-
\end{abstract}

terol were not significantly different when comparing healthy subjects and each diabetic group. Apolipoprotein A-I was lower $(p<0.05)$ in all diabetic groups as compared to healthy subjects (nephropathy vs healthy subjects): $1.50 \pm 0.25$ vs $1.69 \pm 0.32 \mathrm{~g} / 1$ (mean $\pm \mathrm{SD}$ ). Triglyceride was higher $(p<0.05)$ in patients with nephropathy and microalbuminuria as compared to healthy subjects (nephropathy vs healthy subjects): $2.01(0.66-14.7)$ vs 1.09 (0.41$2.75) \mathrm{mmol} / \mathrm{l}$ (median (range)). Apolipoprotein B was higher $(p<0.02)$ in patients with nephropathy as compared to the other three groups (nephropathy vs healthy subjects): $1.54 \pm 0.47$ vs $1.33 \pm 0.30 \mathrm{~g} / \mathrm{l}$. In conclusion, our case-control study has confirmed that Type 2 diabetic patients with increased urinary albumin excretion frequently suffer from dyslipidaemia and cardiovascular disease. However, our study revealed no significant elevation in serum concentration of apo(a) in patients with diabetic nephropathy, but numbers were small.

Key words: Type 2 (non-insulin-dependent) diabetes mellitus, diabetic nephropathy, apolipoprotein(a), cardiovascular disease, lipid metabolism.
Type 2 (non-insulin-dependent) diabetic patients have higher morbidity and mortality from ischaemic heart disease than the non-diabetic background population [1]. The prevalence of ischaemic heart disease, evaluated by electrocardiography (Minnesota Rating Scale), increases with increasing albuminuria [2]. The prevalence of proteinuria is $14 \%$ in Type 2 diabetic patients. Such patients have a five times higher mortality than the non-diabetic background population mainly due to cardiovascular disease [3]. Abnormalities in well-established risk factors (e.g. dyslipidaemia, arterial hypertension, smoking and body mass index) cannot account for this finding. Therefore it would be of interest to try to identify other possible risk factors that would predispose Type 2 diabetic patients with diabetic nephropathy to macrovascular disease.
Lipoprotein(a) ( $L p(a))$ is a macromolecular complex assembled from low-density lipoprotein (LDL) and a large glycoprotein, apolipoprotein(a) (apo(a)) which has homology to plasminogen [4]. In recent years several studies have shown raised levels of serum $\mathbf{L p}$ (a) to be a strong independent risk factor for premature ischaemic heart disease in subjects with and without familial hypercholesterolaemia [5-7]. In patients with familial hypercholesterolaemia it has been suggested that elevated $L p(a)$ is a genetic trait predisposing to ischaemic heart disease [8]. The physiological function of apo(a) has not been clarified in detail. Seventy percent of the variation in serum apo(a) concentration is genetically determined [9]. Apo(a) has been found in arterial walls, and a positive correlation between the serum apo(a) concentration and 
concentrations of apo(a) in the arterial walls has been found in patients undergoing coronary bypass [10].

The aim of our case-control study was to determine the level of apo(a) and its possible relationship to ischaemic heart disease in Type 2 diabetic patients with and without diabetic nephropathy.

\section{Subjects and methods}

\section{Subjects}

All Type 2 diabetic patients attending the outpatient clinic at Hvidöre Hospital were screened for albuminuria and 45 Type 2 diabetic patients with diabetic nephropathy (biopsy verified $n=24$ and clinical criteria $n=21$ ) were identified. Diabetic nephropathy was diagnosed clinically if the following criteria were fulfilled: persistent urinary albumin excretion above $300 \mathrm{mg} / 24 \mathrm{~h}$, presence of diabetic retinopathy and no clinical or laboratory evidence of other kidney or renal tract disease [11]. Exclusion criteria were: renal replacement therapy $(n=3)$, treatment with lipid-lowering agents $(n=3)$ and drug or alcohol abuse $(n=2)$. The remaining 37 patients with diabetic nephropathy were included. Thirty-seven Type 2 diabetic patients with microalbuminuria (urinary albumin excretion rate $31-300 \mathrm{mg} / 24 \mathrm{~h}$ ) and 37 Type 2 patients with normoalbuminuria (urinary albumin excretion rate $\leq 30 \mathrm{mg} / 24 \mathrm{~h}$ ), matched for sex, age and known duration of diabetes were also included in the study. Type 2 diabetes was diagnosed according to the World Health Organisation (WHO) criteria, in all insulin-treated patients stimulated plasma C-peptide values were above $0.6 \mathrm{nmol} / \mathrm{l}[12,13]$. Furthermore, 37 healthy subjects matched for sex and age were investigated. All subjects included in the study were Caucasians, and all gave informed consent to participate in the study. The study was approved by the local ethics committee.

\section{Methods}

All examinations were performed in the morning. Arterial blood pressure was measured twice, on the right arm, after at least $10 \mathrm{~min}$ rest in the supine position and averaged. The measurements were carried out with an appropriately sized cuff using an automatic, electronic device (Takeda Medical UA-751, Tokyo, Japan) [14]. Venous blood samples were drawn after an overnight fast. The laboratory was unaware of the group to which the samples belonged. Lipoproteins, lipids, haemoglobin $\mathrm{A}_{1 \mathrm{c}}\left(\mathrm{HbA}_{1 \mathrm{c}}\right)$, glucose and creatinine were measured using standard methodology. Serum apo(a) concentrations were measured in samples stored at $-70^{\circ} \mathrm{C}$ for up to 2 months, using the Pharmacia Apo(a) assay (Pharmacia Diagnostic AB, Uppsala, Sweden). The principle is a two-site immunoradiometric assay (2-site IRMA) using two different monoclonal antibodies directed against two different epitopes on the apo(a). After hydrolysis and dilution the serum sample was incubated with an excess of ${ }^{125}$ I-labelled anti-apo(a)-antibody and an anti-apo(a)-antibody coupled to solid phase, micro-Sepharose. Antibody-antigen complexes were separated from unbound ${ }^{125}$ I-labelled antibody by centrifugation and the radioactivity was measured. A standard curve was constructed for each assay. No cross-reactivity was seen with either apolipoprotein B or plasminogen, even at concentrations several-fold greater than the normal serum concentrations. The interassay coefficient of variation for apo(a) assays was $5.2 \%$ at $190 \mathrm{U} / 1$ and $6.4 \%$ at $500 \mathrm{U} / \mathrm{l}$. The same human serum control with a high concentration of apo(a) was included in each series. The inter-assay coefficient of variation of this serum control was $7.3 \%$ at a mean of $736 \mathrm{U} / \mathrm{l}$. No inter-batch location bias was observed, using this control. In this study the detection limit of the apo(a) assay was $20 \mathrm{U} / \mathrm{l}$. Results are expressed in terms of the Pharmacia standard, which is apo(a), in U/1 (1 U/1 apo(a) approximates $0.7 \mathrm{mg} / \mathrm{l} \mathrm{Lp}(\mathrm{a})$ ). The con- version factor has been obtained by using a highly purified, commercial Lp(a) preparation from Immuno AG (Vienna, Austria). It is not possible to accurately express the concentration of apo(a) in mass unit as there are at least 6-12 different isoforms with molecular weights varying from 300000 to $700000 \mathrm{Da}$. Thus, each patient sample will contain different proportions of different isoforms. Therefore, no exact conversion factor can be given between units of apo(a) and milligrams of $\mathrm{Lp}(\mathrm{a})$.

Apolipoprotein A-1 and apolipoprotein B were measured by end-point turbidimetry, with commercially available antisera and standards (Hoffmann-La Roche, Basel, Switzerland). Serum cholesterol and triglyceride were measured enzymatically using CHODPAP and GPO-PAP reagents from Boehringer-Mannheim GmbH, (Mannheim, FRG). High-density lipoprotein (HDL)-cholesterol was measured after precipitation of apolipoprotein B containing lipoprotein with phosphotungstic acid [15]. Low-density lipoprotein (LDL)-cholesterol was calculated by the Friedewald equation [16]. $\mathrm{HbA}_{1 \mathrm{c}}$ was determined by high performance liquid chromatography (DIAMAT Analyzer; BIO-RAD, Calif., USA) [17]. Normal range of $\mathrm{HbA}_{1 \mathrm{c}}$ in our laboratory is $4.1-6.1 \%$. Serum glucose concentration was determined by hexokinase method [18]. Serum creatinine concentration was assayed by a kinetic Jaffe' method [19].

At least three $24 \mathrm{~h}$ urine samples were collected. The urinary albumin concentration was determined by radioimmunoassay with a single antibody [20]. Body mass index (BMI) was calculated as weight $(\mathrm{kg}) /$ height $(\mathrm{m})^{2}$. Retinopathy was assessed by fundus photography after pupillary dilation. A 12-lead electrocardiogram (ECG) was recorded. The ECG was coded independently by two trained observers using the Minnesota Rating Scale [21]. Ischaemic heart disease was diagnosed if ECG showed signs of probable myocardial infarction (Minnesota Rating Scale 1.1-2) or possible myocardial ischaemia (Minnesota Rating Scale $1.3,4.1-4,5.1-3$ or 7.1 ). The WHO cardiovascular questionnaire [22] was used to assess past and present history of myocardial infarction, angina pectoris, stroke and intermittent claudication. Macrovascular disease included ischaemic heart, peripheral vascular and cerebrovascular disease. Positive manifestations were ischaemic heart disease as defined above, or a history of angina, myocardial infarction, transient ischaemic attack, stroke, intermittent claudication, rest pain, limb amputation or arterial surgery. Present medication and smoking habits were recorded. Smokers were defined as persons smoking more than one cigarette per day, all others being classified as non-smokers.

\section{Statistical analysis}

Urinary albumin excretion, serum triglyceride, serum creatinine and apo(a) are given as medians (range) all other values are given as means $\pm \mathrm{SD}$.

In comparison of the non-normally distributed continuous variables: urinary albumin excretion, serum triglyceride, serum creatinine and apo(a) the Kruskall-Wallis test of variance was used in order to test for differences between the four groups. If differences were found, the Mann-Whitney test was used for comparisons between two groups. For all other normally distributed variables analysis of variance (ANOVA) was performed in order to test for differences between the four groups. If differences were found the Student's $t$-test was used for comparison between two groups. In order to account for differences in BMI between the four groups covariance analysis with BMI was performed for total-cholesterol, HDL-cholesterol and LDL-cholesterol. If differences were found the Student's $t$-test was used in the covariance analysis for comparison between two groups. All given $p$-values for total-cholesterol, HDL-cholesterol and LDL-cholesterol are thus adjusted for differences in BMI among the four groups. The chi-square test was used for evaluating frequencies.

For correlation analysis, Pearson's correlation coefficient was calculated. Serum triglyercide, serum creatinine, apo(a) and urinary albumin excretion rate were logarithmically transformed before inclusion in the analysis. A $p$-value (two-tailed) less than 0.05 was con- 
Table 1. Clinical characteristics of Type 2 diabetic patients with nephropathy (group 1), with microalbuminuria (group 2), with normoalbuminuria (group 3) and in healthy subjects (group 4)

\begin{tabular}{|c|c|c|c|c|c|}
\hline & Group 1 & Group 2 & Group 3 & Group 4 & $p$-value \\
\hline Sex (male/female) & $30 / 7$ & $30 / 7$ & $30 / 7$ & $30 / 7$ & NS \\
\hline Age $(\text { years })^{f}$ & $61(8)$ & $61(8)$ & $59(7)$ & $61(8)$ & NS \\
\hline $\begin{array}{l}\text { Body mass index } \\
\left(\mathrm{kg} / \mathrm{m}^{2}\right)\end{array}$ & $29.8(5.3)$ & $28.4(4.2)$ & $27.2(4.1)$ & $25.5(4.0)$ & $<0.01^{b, c, d},<0.05^{e}$ \\
\hline $\begin{array}{l}\text { Serum creatinine } \\
(\mu \mathrm{mol} / \mathrm{l})\end{array}$ & $105(54-740)$ & $74(51-173)$ & $76(50-120)$ & $80(62-120)$ & $<0.01^{a, b, c}$ \\
\hline $\begin{array}{l}\text { Retinopathy } \\
\text { (nil/simple/proliferative) }(n)\end{array}$ & $7 / 28 / 2$ & $17 / 20 / 0$ & $20 / 17 / 0$ & - & $<0.05^{\mathrm{a}},<0.01^{\mathrm{b}}$ \\
\hline $\begin{array}{l}\text { Antidiabetic treatment } \\
\text { (diet/oral agents/insulin) }(n)\end{array}$ & $4 / 15 / 18$ & $5 / 20 / 12$ & $9 / 17 / 11$ & - & NS \\
\hline $\begin{array}{l}\text { Receiving antihypertensive treatment }(n) \\
\text { (one drug/two drugs/three drugs) }\end{array}$ & $30(18 / 9 / 3)$ & $15(10 / 4 / 1)$ & $10(8 / 0 / 2)$ & 0 & $<0.01^{\mathrm{a}, \mathrm{b}, \mathrm{c}, \mathrm{d}, \mathrm{e}}$ \\
\hline $\begin{array}{l}\text { Diuretic/ACE-inhibitor/ } \\
\beta \text {-blocker/Ca-antagonist }(n)\end{array}$ & $24 / 6 / 6 / 8$ & $12 / 2 / 6 / 1$ & $7 / 3 / 3 / 1$ & - & $<0.01^{\mathrm{a}, \mathrm{b}}$ \\
\hline
\end{tabular}

${ }^{a}$ (group 1 vs group 2), ${ }^{b}$ (group 1 vs group 3$),{ }^{c}$ (group 1 vs group 4), ${ }^{d}$ (group 2 vs group 4), ' (group 3 vs group 4)

${ }^{\mathrm{f}}$ Mean (SD), ${ }^{\mathrm{g}}$ median (range)

Table 2. Serum concentrations of lipoproteins, lipids and haemoglobin $A_{1 c}$ in Type 2 diabetic patients with nephropathy (Group 1), with microalbuminuria (Group 2), with normoalbuminuria (Group 3) and in healthy subjects (Group 4)

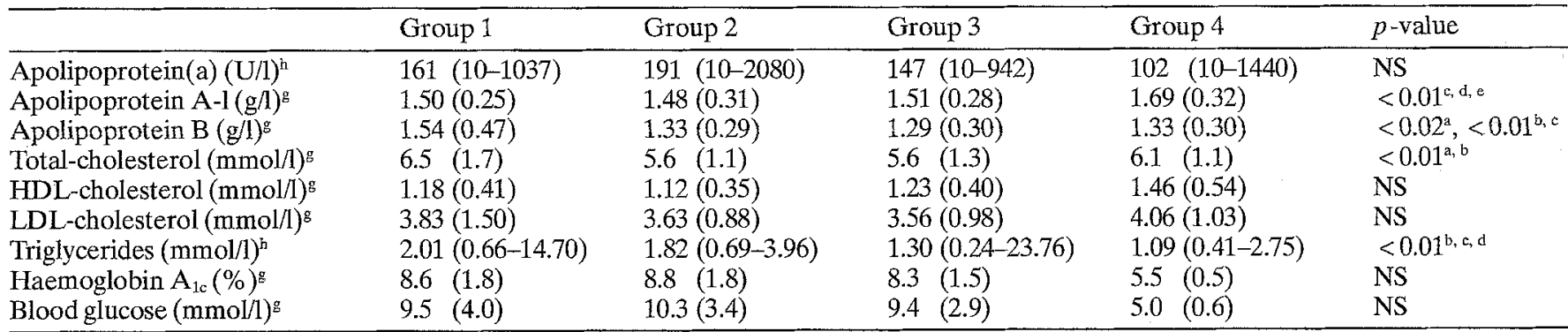

aroup 1 vs group 2), ${ }^{b}$ (group 1 vs group 3), ${ }^{\circ}$ (group 1 vs group 4), ${ }^{d}$ (group 2 vs group 4 ), ${ }^{\circ}$ (group 3 vs group 4 )

${ }^{\mathrm{t}}$ Mean (SD) and ${ }^{\mathrm{g}}$ median (range)

sidered statistically significant. All calculations were made with a commercially available program, Statgraphic (STSC, Rockville, Md., USA).

\section{Results}

The groups were well matched with regard to sex, age and for the diabetic groups also with regard to known duration of diabetes (Table 1). BMI was higher in the diabetic groups as compared to the healthy subjects $(p<0.05)$, and higher in the nephropathic group as compared to the normoalbuminuric group $(p<0.01)$ (Table 1$)$. It should be stressed that many of the albuminuric patients had oedema $(n=14)$ despite diuretic treatment. The frequency of retinopathy was higher in the nephropathic group as com- pared to the microalbuminuric group $(p<0.05)$ and as compared to the normoalbuminuric group $(p<0.01)$ (Table 1). Patients in the nephropathic group had higher systolic and diastolic blood pressure than patients in the normoalbuminuric group and the healthy subjects $(p<0.02)$, respectively (Table 1$)$. Patients in the microalbuminuric group had higher systolic blood pressure than the healthy subjects $(p<0.01)$ (Table 1$)$. The frequency of antihypertensive treatment was higher in all diabetic groups than in healthy subjects $(p<0.01)$ and higher in the nephropathic group as compared to the micro- and the normoalbuminuric group $(p<0.01)$, respectively (Table 1).

The level of apo(a) was not significantly different when comparing the four groups (Table 2). There was no significant difference in the level of apo(a) comparing all 


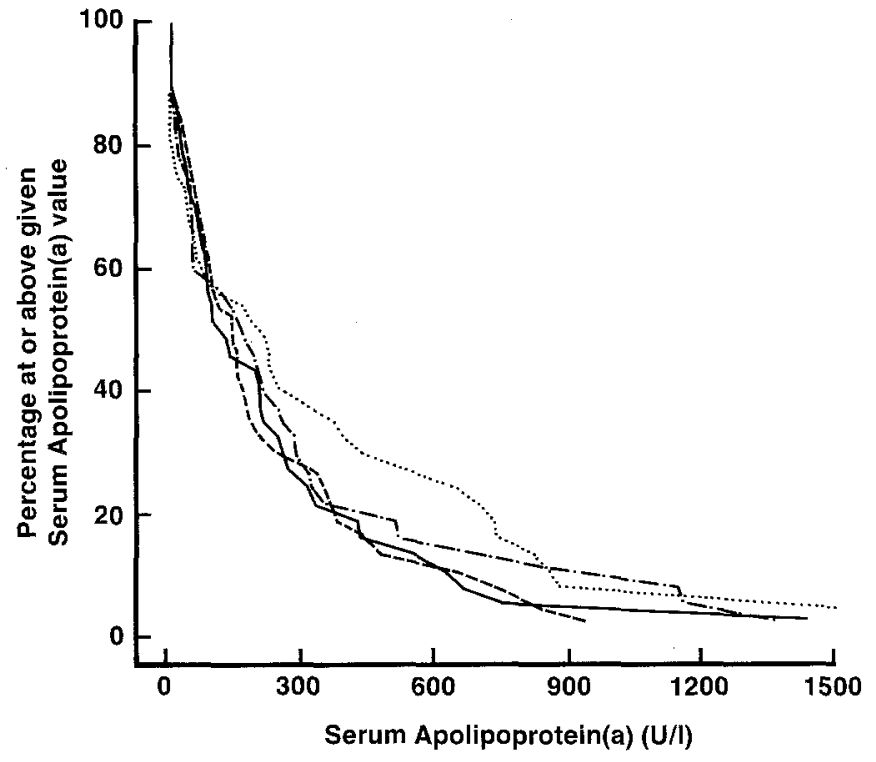

Fig.1. Decremental percentage frequency distribution of serum apolipoprotein(a) in 37 Type 2 diabetic patients with diabetic nephropathy $(-\cdot-\cdot), 37$ Type 2 diabetic patients with microalbuminuria $(\cdots), 37$ Type 2 diabetic patients with normoalbuminuria $(-)$ and in 37 healthy subjects $(---)$

diabetic subjects to the healthy subjects. Eleven of $37(30 \%)$ patients with nephropathy, 14 of $37(38 \%)$ patients with microalbuminuria, 10 of $37(27 \%)$ patients with normoalbuminuria and 15 of $37(41 \%)$ healthy subjects had apo(a) levels of $300 \mathrm{U} / 1$ or more (Fig.1). In 41 diabetic patients with ischaemic heart disease the apo(a) level was 114 (20-2080) U/l compared to 159 (20$1310) \mathrm{U} / \mathrm{l}(p=0.9)$ in diabetic patients without ischaemic heart disease. Likewise no difference was found in apo(a) levels comparing diabetic patients with $(n=58)$ or without $(n=53)$ macrovascular disease, $147(20-2080)$ vs $159(20-1160) \mathrm{U} / \mathrm{l}$, respectively $(p=0.7)$. No correlations were found between apo(a) and age, sex, duration of diabetes, BMI, creatinine, urinary albumin excretion, blood pressure, total-cholesterol, HDL-cholesterol, triglycerides, apolipoprotein A-I, apolipoprotein B or glycaemic control. The frequency of ischaemic heart disease (resting ECG, Minnesota Rating Scale) was higher in all diabetic groups as compared to the healthy subjects $(p<0.05)$, and higher in patients with nephropathy than in patients with normoalbuminuria $(p<0.01)$ (Table 3$)$. A WHO questionnaire revealed a higher frequency of myocardial infarction in the past in all diabetic groups than in healthy subjects $(p<0.05)$ (Table 3$)$. The questionnaire showed at the present a higher frequency of angina pectoris and intermittent claudication in patients with nephropathy and in patients with microalbuminuria as compared to the healthy subjects $(p<0.05)$ (Table 3 ). The prevalence of present smokers was lower in the macroalbuminuric group as compared to the other two diabetic groups $(p<0.05)$ but not different from the healthy subjects.

The level of apolipoprotein A-1 was lower in all diabetic groups as compared to the healthy subjects $(p<0.01)$ (Table 2). The level of apolipoprotein B was higher in patients with nephropathy as compared to all other groups $(p<0.02)$ (Table 2$)$. Total cholesterol was higher in patients with nephropathy as compared to patients with microalbuminuria and to patients with normoalbuminuria $(p<0.01)$ (Table 2). HDL-cholesterol and LDL-cholesterol were not significantly different comparing the four groups. Triglycerides were higher in the nephropathic and the microalbuminuric group as compared to the healthy subjects $(p<0.01)$ and higher in the nephropathic group as compared to the normoalbuminuric group $(p<0.01)$ (Table 2$)$. No significant differences were found in cholesterol $(6.1 \pm 1.4$ vs $5.9 \pm 1.7 \mathrm{mmol} / \mathrm{l} \quad(p=0.7))$ or in apolipoprotein A-1 $(1.49 \pm 0.3$ vs $1.49 \pm 0.3 \mathrm{~g} / 1(p=0.9))$ between micro- and macroalbuminuric patients with $(n=45)$ or without antihypertensive treatment $(n=29)$, respectively. $\mathrm{HbA}_{1 \mathrm{c}}$ and fasting blood glucose were not different in the diabetic groups.

\section{Discussion}

Studies dealing with non-diabetic subjects have demonstrated that elevated apo(a) levels are an independent risk factor for premature ischaemic heart disease [5-8]. Our case-control study has demonstrated that the prevalence of cardiovascular disease increases with increasing albuminuria in Type 2 diabetic patients. However, the level of apo(a) was not significantly different in Type 2 diabetic

Table 3. Prevalence of cardiovascular disease and smoking habits in Type 2 diabetic patients with nephropathy (Group 1), with microalbuminuria (Group 2), with normoalbuminuria (Group 3) and in healthy subjects (Group 4)

\begin{tabular}{|c|c|c|c|c|c|}
\hline & Group 1 & Group 2 & Group 3 & Group 4 & $p$-value \\
\hline $\begin{array}{l}\text { ECG Minnesota Rating Scale } \\
\text { Ischaemic heart disease }(\%)\end{array}$ & 57 & 35 & 19 & 2. & $<0.01^{\mathrm{b}, \mathrm{c}, \mathrm{e}}, 0.05^{\mathrm{f}}$ \\
\hline $\begin{array}{l}\text { WHO Questionnaire } \\
\text { History of } \\
\text { Myocardial infarction (\%) } \\
\text { Stroke (\%) }\end{array}$ & $\begin{array}{l}14 \\
11\end{array}$ & $\begin{array}{r}11 \\
5\end{array}$ & $\begin{array}{r}14 \\
8\end{array}$ & $\begin{array}{l}0 \\
0\end{array}$ & $\begin{array}{l}<0.05^{c, \mathrm{e}, \mathrm{f}} \\
<0.05^{\mathrm{c}}\end{array}$ \\
\hline $\begin{array}{l}\text { Present } \\
\text { Angina pectoris (\%) } \\
\text { Intermittent claudication (\%) } \\
\text { Smoking }(\%)\end{array}$ & $\begin{array}{l}14 \\
30 \\
43\end{array}$ & $\begin{array}{l}16 \\
27 \\
76\end{array}$ & $\begin{array}{r}3 \\
11 \\
70 \\
\end{array}$ & $\begin{array}{r}0 \\
3 \\
51\end{array}$ & $\begin{array}{l}<0.05^{\mathrm{c}, \mathrm{d}},<0.01^{\mathrm{e}} \\
<0.05^{\mathrm{b}},<0.01^{\mathrm{c}, \mathrm{e}} \\
<0.01^{\mathrm{a}},<0.05^{\mathrm{b}, \mathrm{e}}\end{array}$ \\
\hline
\end{tabular}

${ }^{\mathrm{a}}$ (group 1 vs group 2), ${ }^{\mathrm{b}}$ (group 1 vs group 3), ${ }^{\mathrm{c}}$ (group 1 vs group 4), ${ }^{\mathrm{d}}$ (group 2 vs group 3), ${ }^{\mathrm{e}}$ (group 2 vs group 4), ${ }^{\mathrm{f}}$ (group 3 vs group 4 ) 
patients with diabetic nephropathy compared to Type 2 diabetic patients with microalbuminuria and normoalbuminuria and to healthy subjects, but the numbers were small. The four groups were well matched for sex, age and the diabetic groups for known duration of diabetes.

Little information is available concerning the serum level of apo(a) in Type 2 diabetic patients. Schernthaner et al. [23] found no difference in mean or median $L p(a)$ concentrations between patients without retinopathy and nephropathy $(n=38)$ and non-diabetic patients $(n=36)$. However, $14 \%$ of diabetic subjects had Lp(a) concentration greater than $20 \mathrm{mg} / \mathrm{dl}$ as compared with only $5 \%$ of control subjects. No distinction was made between Type 1 (insulin-dependent) and Type 2 diabetic subjects. Ruotolo et al. [24] found no difference in serum apo(a) levels comparing normoalbuminuric Type 2 diabetic patients $(n=12)$ with non-diabetic control subjects $(n=12)$. Guillausseau et al. [25] found higher levels of $L p(a)$ in Type 2 $(n=90)$ and in Type $1(n=36)$ diabetic patients as compared to a healthy control group $(n=78)$. No comparison of the level of $L p(a)$ in patients with different degrees of urinary albumin excretion was done. The mean age of the control subjects was 41 years whereas it was 61 years in the Type 2 diabetic patients. Although $L p(a)$ is mainly genetically determined comparisons should be made between age- and sex-matched groups $[4,7,26]$. Haffner et al. [27] found no difference in $\mathrm{Lp}$ (a) comparing Type 2 diabetic patients $(n=260)$ with age- and sex-matched non-diabetic subjects $(n=336)$. Patients with proteinuria, $\geq 1+$ on Ames Albustix, $(n=34)$ had slightly higher $L p(a)$ levels than those without proteinuria $(n=182)$, but the difference was not statistically significant. In contrast Jenkins et al. [28] found higher levels of apo(a) in Type 2 diabetic patients with micro- $(n=26)$ and macroalbuminuria $(n=19)$ compared to non-diabetic control subjects $(n=140)$. All diabetic patients had an overnight fast before blood samples were drawn in the morning whereas only 44 of the control subjects had been fasting. Recently Emancipator [29] has shown a $14 \%$ reduction in the $2 \mathrm{~h}$ postprandial apo(a) levels compared with fasting levels in the same subjects $(n=51)$. This suggests that standardization of sample collection is essential. All subjects in our study had an overnight fast before blood samples were drawn in the morning. Although we found higher levels of apo(a) in patients with nephropathy and in patients with microalbuminuria compared to normoalbuminuric patients and healthy subjects the differences did not reach statistical significance, but it should be stressed that apo(a) has a highly skewed distribution and the risk of both type 1 and type 2 error increases when the number of patients is small. Recently Parving et al. [11] have shown that only $70 \%$ of Type 2 diabetic patients with albuminuria suffer from diabetic nephropathy. Only patients fulfilling the previously described criteria for diabetic nephropathy were included in our study, while information on the cause of albuminuria are lacking in the above-mentioned studies.

Conflicting results concerning the plasma level of apo(a) have been reported in Type 1 diabetic patients. Kapelrud et al. [30] found higher serum levels of apo(a) in Type 1 diabetic patients with microalbuminuria as com- pared to normoalbuminuric patients. No patients with diabetic nephropathy were included in that study. Jenkins et al. [31] found higher plasma levels of apo(a) in Type 1 diabetic patients with albuminuria or microalbuminuria as compared to normoalbuminuric patients. In contrast Gall et al. [32] found similar serum levels of apo(a) in Type 1 diabetic patients as compared to healthy subjects and no differences in apo(a) levels between patients with nephropathy, microalbuminuria or normoalbuminuria. Furthermore, Winocour et al. [33] found no difference in serum apo(a) in Type 1 diabetic patients with albuminuria as compared to patients with normoalbuminuria but they found higher levels of serum apo(a) in patients with microalbuminuria as compared to patients with normoalbuminuria. O'Donnell et al. [34] found no difference in serum apo(a) comparing normo- and microalbuminuric diabetic patients.

Increased apo(a) levels have been reported in nondiabetic patients with heavy proteinuria of different origin [35]. Detailed analysis revealed that elevated apo(a) was found in, e.g. membranoproliferative glomerulonephritis while normal values were detected in, e.g. minimal change disease. All patients in our nephropathic group had diabetic nephropathy either biopsy verified or diagnosed clinically according to established criteria [11]. Apo(a) is increased in patients with end-stage renal disease compared to patients with a well-functioning kidney transplant [36]. Recently Black et al. [37] showed that patients suffering end-stage renal disease had raised serum levels of apo(a) which fell to near normal level after a successful renal transplant. In our study we found no correlation between serum creatinine and serum apo(a). Three patients with diabetic nephropathy in renal replacement therapy were excluded from our study.

Our cross-sectional study revealed no significant relationship between serum concentrations of apo(a) and ischaemic heart disease and other macrovascular manifestations which is accordance with the much larger population based San Antonio Heart Study of 260 Type 2 diabetic patients [27]. Similar findings have been reported in 188 Type 1 diabetic patients [38]. Furthermore, a longitudinal study of 24 Type 2 diabetic and 11 Type 1 diabetic patients who died of coronary heart disease revealed no significant elevation in serum levels of apo(a) compared to matched diabetic patients who remained alive (control subjects) [39]. In contrast Jenkins et al. [28] found significantly higher apo(a) levels in Type 2 diabetic patients with macrovascular disease $(n=49)$ than in those without $(n=54)$. The present and previous cross-sectional studies may have been subject to a varying degree of survival bias, i. e. diabetic patients with elevated apo(a) levels might be less likely to survive, thus reducing the average apo(a) concentrations in the survivors. However, this suggestion was not supported in the above-mentioned longitudinal study of Type 2 diabetic patients [39].

The distribution of apo(a) shows marked ethnic differences with higher levels in Blacks as compared to Caucasians [4]. Only Caucasians were included in our study. Pharmacological intervention has shown that treatment with nicotinic acid reduces apo(a) concentrations in hyperlipidaemic subjects $[40,41]$, whereas other lipid- 
lowering drugs, including cholestyramine [8] and HMG CoA reductase inhibitors $[8,42]$, appear to have no effect on the apo(a) levels. No patients received lipid-lowering drugs in our study.

Apolipoprotein B and total-cholesterol were significantly higher in our Type 2 diabetic patients with nephropathy as compared to Type 2 diabetic patients with microand normoalbuminuria. Apolipoprotein A-l was significantly lower in all diabetic groups as compared to healthy subjects. Triglycerides were significantly higher in Type 2 patients with nephropathy and microalbuminuria as compared to healthy subjects and significantly higher in patients with nephropathy as compared to patients with normoalbuminuria. This confirms and extends earlier studies dealing with lipids and lipoproteins in Type 2 diabetic patients with and without nephropathy [43].

BMI and frequency of antihypertensive treatment were significantly higher in all diabetic groups as compared to the healthy subjects and within the diabetic patients significantly higher in the nephropathic group as compared to the normoalbuminuric group. It is wellestablished that Type 2 diabetic patients have fluid and sodium retention, particularly pronounced in nephropathic patients, as compared to healthy subjects [44]. This phenomenon will contribute to the elevated BMI. Furthermore, a large number of nephropathic patients were suffering from oedema despite receiving diuretics. To adjust for the differences in BMI between the four groups covariance analysis with BMI was performed for total-cholesterol, HDL-cholesterol and LDL-cholesterol (all normally distributed parameters). All given $p$-values concerning the three cholesterols are thus adjusted for the differences in BMI among the four groups of patients. We cannot exclude the possibility that the difference in frequency of antihypertensive treatment between the four groups contributes to the lipid and lipoprotein abnormalities observed in the diabetic patients, but our analysis of patients with abnormal urinary albumin excretion showed no difference in total-cholesterol and in apolipoprotein A-1 levels comparing patients with or without antihypertensive treatment. In conclusion, our case-control study has confirmed that Type 2 diabetic patients with abnormal urinary albumin excretion frequently suffer from dyslipidaemia and cardiovascular disease. However, our study revealed no significant elevation in serum concentration of apo(a) in patients with diabetic nephropathy and a lack of correlation between apo(a) levels and macrovascular manifestations, but numbers were small.

Acknowledgements. We acknowledge the assistance of Ms U.M. Schmidt, Ms B. Jensen and the laboratory staff at the Steno Diabetes Center in conducting this study. This study was presented in part at the European Association of the Study of Diabetes, Dublin, Ireland, September 1991.

\section{References}

1. Koistinen MJ (1990) Prevalence of asymptomatic myocardial ischaemia in diabetic subjects. Br Med J 301: 92-95

2. Gall M-A, Rossing P, Skøtt P et al. (1991) Prevalence of microand macroalbuminuria, arterial hypertension, retinopathy and large vessel disease in European type 2 (non-insulin-dependent) diabetic patients. Diabetologia 34:655-661

3. Nelson RG, Pettitt DJ, Carraher M-J, Baird HR, Knowler WC (1988) Effect of proteinuria on mortality in NIDDM. Diabetes 37: 1499-1504

4. Utermann G (1989) The mysteries of lipoprotein(a). Science 246: $904-910$

5. Rosengren A, Wilhelmsen L, Eriksson E, Risberg B, Wedel $\mathrm{H}$ (1990) Lipoprotein(a) and coronary heart disease: a prospective case-control study in general population sample of middle aged men. Br Med J 301: 1248-1251

6. Rhoads GG, Dahlen G, Berg K, Morton NE, Dannenberg AL (1986) $\mathrm{Lp}$ (a) lipoprotein as a risk factor for myocardial infarction. JAMA 256: 2540-2544

7. Berg K, Dahlen G, Frick MH (1974) Lp(a) lipoprotein and pre$\beta_{1}$-lipoprotein in patients with coronary heart disease. Clin Genet 6: 230-235

8. Wiklund O, Angelin B, Olofsson S-O et al. (1990) Apolipoprotein(a) and ischaemic heart disease in familial hypercholesterolaemia. Lancet 335: 1360-1363

9. Hasstedt SJ, Williams RR (1986) Three alleles for quantitative Lp(a). Genet Epidemiol 3: 53-55 (Letter)

10. Rath M, Niendorf A, ReblinT, Dietel M, Krebber H-J,BeisiegelU (1989) Detection and quantification of lipoprotein(a) in arterial wall of 107 coronary bypass patients. Arteriosclerosis 9:579-592

11. Parving H-H, Gall M-A, Skøtt P et al. (1992) Prevalence and causes of albuminuria in non-insulin-dependent diabetic patients. Kidney Int 41: 758-762

12. Hother-Nielsen $\mathrm{O}$, Faber $\mathrm{O}$, Sørensen NS, Beck-Nielsen $\mathrm{H}$ (1988) Classification of newly diagnosed diabetic patients as insulin-requiring or non-insulin-requiring based on clinical and biochemical variables. Diabetes Care 11:531-537

13. Faber OK, Binder C (1977) C-peptide response to glucagon: test for the residual $\beta$-cell function in diabetes mellitus. Diabetes 26 : 605-610

14. Wiinberg N, Nygardt J, Sengeløv H, Nielsen PE (1988) Oscillometric measurement of the blood pressure. Ugeskr laeger 150: $1282-1284$

15. Katterman R, Jaworek D, Möller G (1984) Multicenter study of a new enzymatic method of cholesterol determination. J Clin Chem Biochem 22: 245-251

16. Friedewald WT, Levy RI, Frederickson DS (1972) Estimation of the concentration of low-density lipoprotein cholesterol in plas$\mathrm{ma}$, without use of the preparative ultracentrifugation. Clin Chem 18: 499-502

17. Goldstein DE, Peth SB, England JD, Hess RL, Randall LH, DaCosta J (1980) Effects of acute changes in blood glucose on $\mathrm{HbA}_{1 \mathrm{c}}$. Diabetes 29:623-628

18. Andersen I, Hannibal S (1983) Analytical and economical optimization of a glucose method with immobilized enzymes. J Automatic Chemistry 4: 188-192

19. Ullmann R, Bonitz K (1976) Vollmechanisierte kinetische Messung von Kreatinin. Med Labor Bd 29: 137-145

20. Christensen C, Ørskov C (1984) Rapid screening PEG radioimmunoassay for quantification of pathological microalbuminuria. Diabetic Nephropathy 3: 92-94

21. Blackburn H, Keys A, Simonson E, Rautaharju P, Punsar S (1960) The electrocardiogram in population studies: a classification system. Circulation 21: 1160-1175

22. Rose GA, Blackburn H (1968) Cardiovascular survey methods. WHO Monograph Series No. 56: 162-165

23. Schernthaner G, Kostner GM, Dieplinger H, Prager R, Mühlhauser I (1983) Apolipoproteins (A-I, A-II, B) Lp(a), lipoprotein and lecithin: cholesterol acetyltransferase activity in diabetes mellitus. Arteriosclerosis 49: 277-293

24. Ruotolo G, Zoppo A, Parlavecchia M, Giberti B, Micossi P (1991) Apolipoprotein(a) levels in type 1 and type 2 diabetes mellitus. Acta Diab 28: 158-161

25. Guillausseau P-J, Peynet J, Chanson P et al. (1992) Lipoprotein(a) in diabetic patients with and without chronic renal failure. Diabetes Care 15: $976-979$ 
26. Kostner G, Klein G, Krempler F (1984) Can serum lipoprotein $\mathrm{Lp}$ (a) concentrations be lowered by drugs and/or diet? In: Carlsson LA, Olsson AG (eds) Treatment of hyperlipoproteinaemia. Raven Press, New York, pp 151-156

27. Haffner SM, Morales PA, Stern MP, Gruber MK (1992) Lp(a) concentrations in NIDDM. Diabetes 41: 1267-1272

28. Jenkins AJ, Stcel JS, Janus ED, Santamaria JD, Best JD (1992) Plasma apolipoprotein(a) is increased in type 2 (non-insulin-dependent) diabetic patients with microalbuminuria. Diabetologia 35: $1055-1059$

29. Emancipator K (1992) Low bias in assayed values of lipoprotein antigens-lipoprotein(a) and apolipoprotein $A-1$ and $B$ - in midday postprandial blood specimens compared with morning fasting specimens. Clin Chem 38: 431-433

30. Kapelrud H, Bangstad H-J, Dahl-Jørgensen K, Berg K, Hanssen $\mathrm{KF}$ (1991) Serum Lp(a) lipoprotein concentrations in insulin dependent diabetic patients with microalbuminuria. Br Med J 303 : $675-678$

31. Jenkins AJ, Steele JS, Janus ED, Best JD (1991) Increased plasma apolipoprotein(a) levels in IDDM patients with microalbuminuria. Diabetes 40:787-790

32. Gall M-A, Rossing P, Hommel E et al. (1992) Apolipoprotein(a) in insulin-dependent diabetic patients with and without diabetic nephropathy. J Clin Lab Invest 52:513-521

33. Winocour PH, Bhatnagar D, Ishola M, Arrol S, Durrington PN (1991) Lipoprotein(a) and microvascular disease in type 1 (insulin-dependent) diabetes. Diabetic Med 8:922-927

34. O'Donnell MJ, Bain SC, Barnett AH, Jones A (1991) Lp(a) concentrations. Br Med J 303: 1134 (Letter)

35. Karádi I, Romics L, Pálos G et al. (1989) Lp(a) lipoprotein concentration in serum of patients with heavy proteinuria of different origin. Clin Chem 35: 2121-2123

36. Cressman MD, Hoff HF, Nally JV Jr, Schreiber M Jr, Van Lente F (1991) Lipoprotein(a) and the cardiovascular risk of end stage renal disease. J Am Soc Nephrol 234 (Abstract)

37. Black IW, Wilcken DE (1992) Decreases ix apolipoprotein(a) after renal transplantation: implications for lipoprotein(a) metabolism. Clin Chem 38: 353-357
38. Orchard T, Usher D, Maser R, Stein E, Manderino A (1992) Does Lp (a) relate to complications of IDDM? The Pittsburg epidemiology of diabetes complications study (EDC). Diabetes 41: 31 A (Abstract)

39. Haffner SM, Moss SE, Klein BEK, Klein R (1992) Lack of association between lipoprotein (a) concentrations and coronary heart disease mortality in diabetes: the Wisconsin epidemiologic study of diabetic retinopathy. Metabolism 41: 194-197

40. Carlsson LA, Hamten A, Asplund A (1989) Pronounced lowering of serum levels of lipoprotein Lp(a) in hyperlipidaemic subjects treated with nicotinic acid. J Intern Med 226:271-276

41. Noma A, Meada S, Okuno M, Abe A, Muto Y (1990) Reduction of serum lipoprotein(a) levels in hyperlipidaemic patients with $\alpha$-tocopheryl nicotinate. Arteriosclerosis 84: 213-217

42. Thiery J, Armstrong VW, Schleef J, Creutzfeldt C, Creutzfeldt W, Siedel D (1988) Serum lipoprotein Lp(a) concentrations are not influenced by an HMG CoA reductase inhibitor. Klin Wochenschr 66: 462-463

43. Betteridge DI (1989) Lipids, diabetes, and vascular disease: the time to act. Diabetic Med 6: 195-218

44. Wiedmann P, Beretta-Piccoli C, Keusch G et al. (1979) Sodiumvolume factor, cardiovascular reactivity and hypotensive mechanism of diuretic therapy in mild hypertension associated with diabetes mellitus. Am J Med 67:779-784

Received: 17 September 1992

and in revised form: 28 December 1992

Dr. F.S. Nielsen

Steno Diabetes Center

Niels Steensens Vej 2

DK-2820 Gentofte

Denmark 